\title{
House Garden as a Symbol of Place, Identity and Sense of Belonging for Low-Cost Flat Residents in Urbanizing Malaysia
}

\author{
Suriati Ghazali
}

\begin{abstract}
House garden symbolized people's place, identity and sense of belonging. These subjective elements of house gardens is less realized by the gardeners themselves, however, they are evidently important in influencing peoples' behavior in everyday life. This paper will discuss house gardens as symbol of place, identity and sense of belonging for residents in low-income housing area of urban Penang, Malaysia. Multiple methods were used in the collection of data, which include questionnaire survey on 61 low-cost flat residents, in-depth interviews with 15 selected residents and general observation on the gardens owned by the respondents. Two third of the low-cost flats' residents have shown enthusiasm to gardening, in which, they have converted public spaces into private gardens. Interviews revealed that house gardens proved their attachment to place, place identity and sense of belonging.
\end{abstract}

Index Terms-House gardens, low-income urban communities, place identity, sense of belonging, Topophilia.

\section{INTRODUCTION}

This paper explores the importance of house gardens in symbolizing one's attachment to place, identity and sense of belonging. All these are subjective elements rooted in a person's personality, which are brought by past childhood experience, socialization, and aspiration. Much significant contribution of house gardens, as discussed by many, is its importance in nurturing relationships between people, communities and the landscape. According to these literature, house gardens satisfies daily food subsistence, lowering every day spending and strengthening relationships between people, communities and the landscape. The objective of this paper is to explore the relevance of subjective elements of place identity and sense of belonging that insist urban residents to resort to gardening.

\section{REVIEW OF LITERATURE}

Past research has shown that gardens work nurture the relationships between people, communities and the landscape - a relationship that contains social, economic and ecological elements [1]. People have been working on house gardens since the early settlement. House gardens are common, ordinary gardens around a house, or substitutes to them, developed for the production of useful, material goods or of

Manuscript received December 15, 2012; revised February 24, 2013. This work was supported by Universiti Sains Malaysia under the Research University Grant 2010-2013.

Suriati Ghazali is with the School of Humanities, Universiti Sains Malaysia (e-mail: suriati@usm.my; suriati8@gmail.com). appreciated nonmaterial values for individual households [2], [3]. Meanwhile for [4] gardens are landscapes that heal, connect and empower people's relations with each other and with the natural world.

Most research agrees on the advantage of house gardens and community gardens for food security to urban community. City dwellers are able to grow their own food, or to donate what they have grown to others [5], [6]. Due to scarcity of private land for house gardening, urban planning in the West put an emphasis on the need of providing green space for the community. This has led to the initiative of providing community gardens. Researchers suggest that community gardens is a way to overcome the scarcity of space, to practice gardening surrounding the house, and at the same time provide fresh produce and plants, improve the neighborhood, strengthen sense of community and sustain connection with the environment [7]. Community gardens often encourage food production by providing gardeners a place to grow vegetables and other crops.

Previous research indicates gardening involves three major environmental influences on longevity: diet, physical activity and psychosocial fulfillment [8]. [9] Highlights that most commonly expressed reasons for participating in community gardens were access to fresh foods, to enjoy nature, and for health benefits. Community gardens provide social benefits, such as the sharing of knowledge on food production with the wider community, and at the same time promote environmental awareness, stewardship of green space, and social equity through shared food production [6]. [10] Discusses that most gardeners in South-east Toronto community gardens were women, but men and children often attend and work in their plots. Regular tasks involved planting, weeding, watering and of course harvesting. The gardens also served as a place for people to gather and socialize, in which growers gather food for meals from the garden almost every day. Gardening can improve one's understanding of the interaction of social and physical environments and community health, and effective strategies for empowerment, development, and health promotion [9], [11].

All of these prove that gardens are important elements in working towards sustainable communities. [12] in her report on Community Gardening states that the most valued social benefits include social diversity, a place to garden, economy, increased self-sufficiency, production of good quality food, and providing a livelihood, especially for seniors. Many believe that public acceptance and enthusiasm for community gardens has blossomed all over the city. Because community gardens offer a space for local residents to meet, they help to 
build a sense of community. This is an important feature for those who would otherwise feel impoverished, and alienated in their urban environment [6]. Hall also suggests that the therapeutic value of gardening activity has improved lifestyles of those who can enjoy them. For example cancer patients participated in gardening activities showed quicker recovery than patients who did not engage in such restorative activity [13].

In Malaysia, there is little discussion on the way house garden symbolized people's place, identity and sense of belonging. Among a few, [14] discusses ethnic gardens in terrace housing, which characteristics are closely related to the residents' cultural background, influenced by cultural values and functional needs, and the identity to specific ethnicity. In earlier studies I highlighted the insistence of the Malays in Malaysia, who were 'trapped' in city villages, to keep a garden around the house, because it is a symbol of identity, sense of place and belonging which is rooted since their ancestors [15], [16]. This fits [17]'s conceptualization on the 'Sense of Place', in which, "To be inside a place is to belong to it and to identify with it, and the more profoundly inside you are the stronger is the identity with the place...".

Similarly, [3] conceptualized this as Topophilia, which explains the affective bond between people and their place in the world. People's relation with nature, their geographical behavior, as well as their feelings and ideas with regard to space and place appear to have an effect upon the differences in the ways that they perceive and are attached to the place [3]. Human experiences, awareness, and knowledge raise different levels of consciousness and perceptions towards place. This results in the various ways in which people respond to place, such as personal and lasting appreciation of landscape [15] - in this case, the house garden.

Community garden concept is considered new in Malaysia. The established garden in Malaysian's lifestyle is house garden or kitchen garden [16], [18], [15]. In my earlier study I discover that urban residents who have access to kitchen garden will enjoy subsistence income, thus gardens provide a supplement to urban income [16], [18]. Hence garden culture remains in urban area.

Increased urbanization in Malaysia and the degradation of yards available in town houses, and also the increasing number of citizens residing in high rise flats resulted in vast number of town people being denied an access to house garden [16], [18]. Because flat residents in Malaysia have no access to private gardens or community gardens, many regard gardening as impossible for them. However elements relating to gardening behavior - mundane behavior which are seemingly small and insignificant, but is in fact significant in their own right [19] - could be witnessed surrounding the high-rise residential areas. It is interesting to understand the residents' passions to gardening, which resulted in some of them struggling to secure some space from the public land surrounding their residential area. This study on flat residents and their gardens will fill in the research gap on how garden symbolizes people's place, identity and sense of belonging in the case of flat residents of Malaysia.

\section{RESEARCH METHODOLOGY}

A township called Sungai Dua, 9 kilometres from
Georgetown capital of Penang, Malaysia, was chosen as study site. This township - a conurbation of Georgetown - is located between the capital to the north and industrial estates 5 kilometres to the south. Sungai Dua is undergoing rapid urban and housing development. Blocks of shop lots and housing estates consisting low- and medium cost flats, terrace and semi-detached houses, and bungalows have been growing in this area since the 1970s.

Data collection was conducted in January 2012 and re-visitation for additional interview was carried out in January 2013. A survey facilitating questionnaires had been conducted on 61 residents of low-cost flats. These low-cost flats are not equipped with space for individual gardens. The sampling technique used to select respondents was a combination of random and systematic sampling. The first house was chosen at random, and the next house was chosen systematically at the interval of 5 houses away from the first house selected. The questionnaires include both close and open ended questions. For a more detailed understanding on the symbols of place, identity and sense of belonging, in-depth interviews were also conducted on eight residents. They were all garden lovers.

\section{RESEARCH FINDINGS AND DISCUSSION}

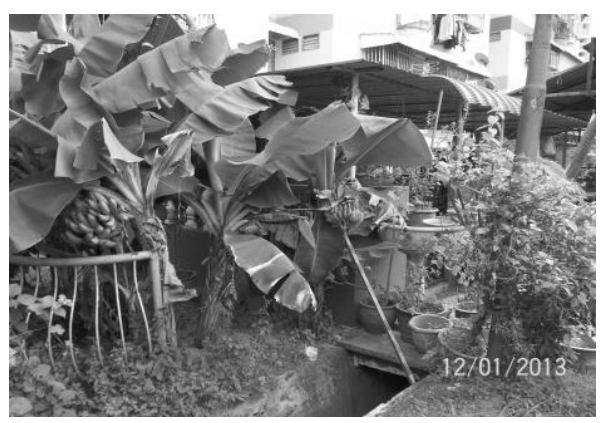

Fig. 1. Residents of a low-cost flat convert public space to kitchen gardens, Photo taken by the author, 2013.

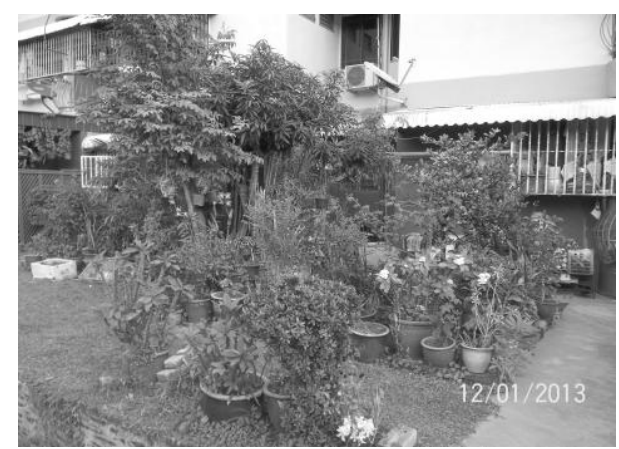

Fig. 2. A resident converted public space at the backyard into a house garden. Photo taken by the author, 2013.

The research result reveals that $68.9 \%$ (42 people) of the flat residents interviewed manage to create a garden for their households, particularly those whose houses are located on the ground floor. In some blocks of the low-cost flats, there is a space of about 5 to 10 feet from the back door of the flat to the drain. By right, this public space should be left inbuilt Nevertheless, 15 respondents, who own a flat on the ground floor, have taken this opportunity to convert the public space 
into kitchen garden (Fig. 1 and 2). The other 17 flat residents who live at the upper level do not have access to this public space. Consequently, they had planted flowers, low-plants and cooking herbs in the pots and arrange them at the corridor in front of their houses - also a public space - or at the back balcony of their flats (Fig. 3). This replicates a garden that they could not afford to have. This situation reveals that house garden is important and appreciated by urban residents living in low-cost flats.

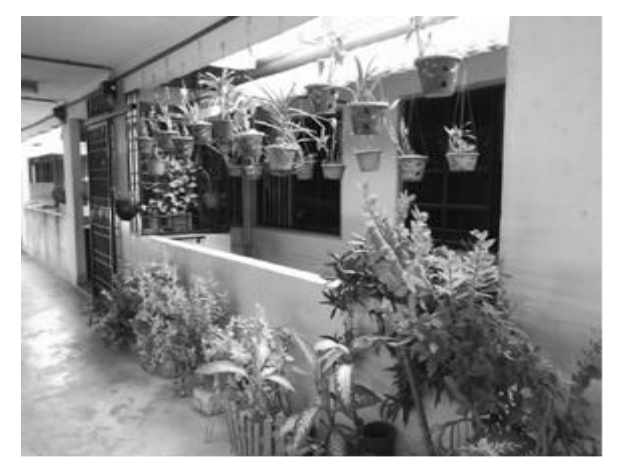

Fig. 3. Residents at the upper level of the flat planted flowers and vegetables in the pot. Photo taken by the author, 2012.

Residents were asked about their preference for gardening. Half of the respondents believed that they resort to gardening because they were once 'kampong (village) people', lived in a kampong house, and were from a family of farmers (21 respondents). This shows the relevance of place, identity and sense of belonging in explaining the reason to gardening, as suggested by [3] and [17]. Eight other respondents, on the other hand, reasoned that they keep a garden because they want their houses to have green plants, therefore they will feel calm, relaxed and comfortable. This awareness on therapeutic elements of the garden has been highlighted by [13]. However two respondents believed that their interest in house gardening was derived after watching television and reading magazines on the benefits of gardening.

\section{A. Place, Identity and Sense of Belonging}

Informal interviews were carried out in January 2012 and January 2013 in order to explore flat residents' imagination of their garden, and the daily experiences which give rise to feelings of belonging and patriotism towards their garden. These are subjective impressions, showing the uniqueness in experiences which influence the way flat residents perceived their gardens.

Residents' past experience and memory living in a kampong or villages surrounded by house gardens have inspired them to make a garden of their own. In addition to this, awareness on the need for edible low-maintenance plants and herbs to be used in the cooking motivated many of them to grow these plants. A lady in her 50s for example, who owns a ground floor flat, uses the $5 \times 10$ feet public space at the backyard of her flat to grow cooking herbs and flowers (Fig. 1). She grows low-maintenance cooking herbs such as pandanus leaves, ginger, lemon grass, turmeric, lime and curry leaves. In this case, it is observed that residents who secured a ground floor unit are more fortunate than those who obtained upper level flats. She reasoned her motives to initiate a kitchen garden as follows:
- I always love gardening. Gardening gives me satisfaction even though in a small area such as this. I am happy to see the plants grow, flower, and have fruits...I feel just nice and happy seeing these even though the produce is not much" (Respondent 1).

She also remembers the advantage of living in a village. She said:

- "Living in a kampong will be more convenient and enjoyable to those who want to own a garden. We may have a larger space area. We will have a front yard, backyard and side yards...we can even plant fruit trees which are much bigger and taller" (Respondent 1).

Rural images in the kampong built environment were recalled by the respondents, in which, houses are surrounded by coconut trees and a variety of fruit trees such as rambutan and mango; and low plants, such as ginger, tumeric and lemongrass. These are considered as important elements in a Malay village [15], [16].

Another respondent, a female respondent, age 40s, originated from a rural village of about 150 kilometers to the north, put an emphasis that her upbringing in a kampong nurture her love to gardens and gardening work. She said:

- "I have resorted to gardening at the backyard of my flat since I move to this flat 15 years ago. I really love gardening...I am the typical kampong person" (Respondent 2).

She plants various types of low-plants in pots and also on the ground. Among her plants are mints, chili, lemongrass, turmeric, ginger, kaffir lime, guava and papaya, and kampong salads. She adds:

- "I feel so pleased and every time I pluck the produce, I usually give some to my neighbors. That makes me feel calm, happy. Gardening and planting all these stuffs are considered my hobby since I was at primary school" (Respondent 2).

Another woman respondent age 40s reveals that it is her husband, originated from a kampong, who loves gardening. She said:

- "This garden is my husband's garden. He grew up in a village nearby this area. Some 20 s years ago this area was a rural area. He really loves gardening but unfortunately the backyard space is too narrow. You can see he grows plenty of vegetables in this small garden. He grows mustard leaves, kangkong, chili and spinach, chives, kaffir lime, betel, pandanus, lemongrass, and varieties of flowers. He tends the garden every day and he grows edible food for cooking. Some of the flowers are in the pots" (Respondent $3)$.

Verbatim words from these residents are examples of emotional attachment and sense of place to the kampong and memory of the past. These elements develop their love to a kampong or characteristics related to it, for example, the kitchen gardens. This proves [3]'s conceptualization on Topophilia and [17]'s theorization on Sense of Place, in that, subjective impression to place and landscape generate love of place, identity and sense of belonging.

\section{B. Neighborliness and Sense of Community}

Research on kampong's social relation agree that the element of neighborliness and mutual help - or gotong royong, induce sense of community which hold a group of people together [15], [16], [20]. All residents who own a garden express their gratitude for being able to share garden 
produce with neighbors and friends.

For example, a woman age 40s, reported that she share produce of her gardens with her neighbors and friends. She said:

- "I am happy to see my plants grow. When they are ready to be plucked, I pluck them for my cookings, and I also give some to my neighbors. Sometimes my neighbors gave me their produce as well. We always spend time talking to each other while tending the garden" (Respondent 4).

She, who regarded the kitchen garden as a 'special space' for her household, also placed a swing and a small table in the garden. She uses this space as a place where she can enjoy chit-chatting with her family members and neighbors. This proves that a house garden is a multi-functional space - that are, economic (productive) space and also social (reproductive) space. The 'productive' function of her garden is that, it is an important supplement to urban income. Meanwhile her garden's 'reproductive' function is that it is a place in which she and her family found relaxing, and a place in which she strengthen familial ties and social networks. The garden is left unfenced because it is, by right, a public space. However both the lady owner and her neighbors have made a 'silent agreement' that the garden is hers.

\section{Struggle for Space}

Because the open public space is scarce, low-cost flat residents have to compete for a space to garden. A few respondents reported bitter experience in establishing their own garden on public space. A woman respondent, age 55, uses her backyard as her kitchen garden similar to the other respondents. In addition, she also converted a public space at the other side of the road as her garden. Therefore, she has a larger kitchen garden compared to her other counterparts. She reasoned:

- "I like gardening but there is no space. Therefore I use the backyard, and also the empty space at the other side of the road, as my kitchen garden. The space there was left empty for some time, therefore it is beneficial if I grow vegetable on it" (Respondent 5).

She grows similar cooking herbs as earlier respondents, but in a larger numbers. In addition, she also grows vegetables such as lady's fingers and egg plants; flowering plants such as orchid, hibiscus and bougainvillea. However, she has a complaint:

- "I have been gardening here for many years. None of the residents here complained about this. However, lately there are people who don't like me doing this (gardening on public space). One morning I discovered my garden at the other side of the road had been destroyed. Someone or maybe a group of people cut my plants down. I felt very disappointed. Then I put a fence around my garden - a simple fence - simply to mark that this is my garden area. I grew vegetables again. Some months later someone destroyed my plants again. And I have to start all over again" (Respondent 5).

This situation can be translated as a struggle for space to garden - a conflict that took an effect in the neighborhood that has limited space to garden. The respondent's experience highlights the importance of introducing community gardens, especially to flat residents that have no space to grow plants and vegetables. This study proved that more than half of the low-cost flat residents would like to have gardens, which will both function as economic and social spaces for them.

The issues of resistance, conflict and competition for space for gardening and other uses among the communities, in this case, flat residents, can be associated with capitalist urban development [15]. There are conflicts between the people and the development agency, when the kampong people are forced to evacuate their village land for the development of housing projects. Kampong people have to compete with the latter on access to the resources in which they (the village people) have previously relied on - the land. In Malaysian cases, the kampong people will usually be paid compensation, either in a form of house/flat or money [15], [16]. In this process uneasiness and conflict occasionally occur, either between development agencies and the people, or between the people. In such conflicts, rurality persists in rapidly-expanding city environments, with the result of people with strong ties to the land having to re-imagine their futures. Thus land becomes a site which can be interpreted as a space for struggle to achieve individual objectives, as cases in this paper presents.

\section{CONCLUSION}

Flat residents surrounding the expanding urban region in Penang have an impact on the urban environment and ways of life. They assert to house gardening on a small public space surrounding their house as an expression of love and appreciation for their kampong and memories of the past. This study strengthens the conceptualization of Sense of Place and Topophilia in understanding people's love for their place, identity, and sense of belonging. City residents' subjective elements interpreted in their insistence to gardening should be understood by city planners. Thus this study implicates a suggestion for a more humanistic approach to deal with subjective elements of the city residents specifically, the inclusion of community gardens in the town planning.

\section{REFERENCES}

[1] S. Irvine, L. Johnson, and K. Peters, "Community gardens and sustainable land use planning: A case-study of the Alex Wilson community garden," Local Environment, vol. 4, no. 1, pp. 33-46, 1999.

[2] C. T. Kimber, "Gardens and dwelling: People in vernacular gardens," The Geographical Review, vol. 94, no. 3, pp. 263-283, 2004.

[3] Y. F. Tuan, Topophilia: A study of environmental perception, attitudes and values, Englewood Cliffs, New Jersey: Prentice-Hall, 1974, pp. 93-113.

[4] A. Wilson, The Culture of Nature: North American landscape from Disney to the Exxon Valdez, Toronto, Canada: Between the Lines, 1991, pp. 11-18.

[5] E. Harris, "The role of community gardens in creating healthy communities," Australian Planner, vol. 46, no. 2, pp. 24-27, June 2009.

[6] D. Hall, "Community Gardens as an Urban Planning Issue," Master of Planning Thesis, School of Community and and Regional Planning, The University of British Columbia, pp. 45-46, 1996.

[7] A. K. Hannah and P. Oh, "Rethinking Urban Poverty: A look at Community Gardens," Bulletin of Science, Technology and Society, vol. 20, no. 3, pp. 207-216, June 2000.

[8] S. Somerset, R. Ball, M. Flett, and R. Geissman, "School-based community gardens: Re-establishing healthy relationships with food," Journal of the Home Economics Institute of Australia, vol. 12, no. 2, pp. 25-33, 2005

[9] D. Armstrong, "A Survey of Community Gardens in Upstate New York: Implications for Health Promotion and Community Development," Health and Place, vol. 6, pp 319-327, December 2000. 
[10] S. Wakefield, F. Yeudall, C. Taron, J. Reynolds, and A. Skinner, "Growing Urban Health: Community Gardening in South East Toronto," Health Promotion International, vol. 22, no. 2, pp. 92-101, Feb. 2007.

[11] L. M. Westphal, "Urban greening and social benefits: A study of empowerment outcomes," Journal of Arboriculture, vol. 29, no. 3, pp. 137-147, 2003.

[12] M. Quayle, Report on Community Gardening in Canada, University of British Columbia, Vancouver, pp. 16, 1986.

[13] D. Malakoff, "What good is Community Greening?" American Community Gardening Association Monograph, Philadelphia, pp. 5-15, 1995.

[14] I. Said, "Pluralism in terrace housing community through ethnic garden," Jurnal Teknologi, vol. 35, pp. 41-53, December 2001.

[15] S. Ghazali, "Sense of place and the politics of insider-ness in villages undergoing transition: the case of city kampung on Penang Island," in Cleavage, Connection and Conflict in Rural, Urban and Contemporary Asia, T. Bunnell, D. Parthasarathy, E. C. Thompson, Eds. Dordrecht, Netherlands: ARI-Springer, ch. 8, pp. 117-142, 2013.

[16] S. Ghazali, "Socio-economic changes in the peri-urban areas in Penang, Malaysia," Ph.D. Thesis, School of Geography, University of Leeds, UK, pp. 132-138, 1999.

[17] E. Relph, Place and Placelessness, London: Pion, pp. 45-50, 1976.

[18] S. Ghazali, "Managing land for housing: A study in peri-urban villages in Penang, Malaysia," Malaysian Journal of Tropical Geography, vol. 31 , no. $1-2$, pp. $75-85,2000$.

[19] E. L. E. Ho and M. Hatfield, "Migration and Everyday Matters," Population, Space and Place, vol. 17, pp. 707-713, 2011.
[20] E. C. Thompson, "Rural villages as socially urban spaces in Malaysia," Urban Studies, vol. 41, no. 12, pp. 2357-2376, 2004.

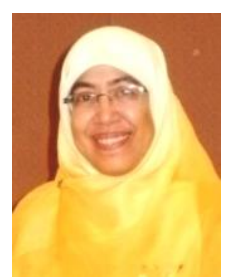

Suriati Ghazali is an associate professor in the School of Humanities, Universiti Sains Malaysia, Pulau Pinang, Malaysia. She holds a PhD degree in Social Geography from the University of Leeds, United Kingdom. Her specializations are Social and Cultural Geographies, Gender Studies and Development Geography. Currently she is teaching Human Geography, Geography of ASEAN and Asia Pacific Countries, and Modern Geographical Thought. She has actively published her work in books and journals. Her latest publication include 'Sense of place and the politics of insider-ness in villages undergoing transition', in T. Bunnell, D. Parthasarathy and E.C. Thompson (eds), Cleavage, Connection and Conflict in Rural, Urban and Contemporary Asia, published by Springer, 2013, pp 117-142; 'Difusi ruangan budaya transsexualisme dan imaginasi geografi pelajar lelaki berpenampilan silang di universiti tempatan Malaysia ('Spatial diffusion of transsexualism and the geographical imagination of male-to-female transsexual students in Malaysian local universities'), published in E-Bangi Journal of Social Science and Humanities, 7(1): 252-266, 2012; 'Knowledge and awareness of Malaysian cancer patients and their family towards facing and coping with cancer', in Health and the Environment Journal, 3 (2): 38-50, 2012, and a research book, Global Ecotourism and Local Communities in Rural Areas, USM Publication, 2011. 